\section{BRAZIULIAN JOURNAL \\ OF MEDICAL AND BIOLOGICAL RESF.ARCH}

www.bjournal.com.br
ISSN 0100-879X

Volume 43 (03) 226-324 March 2010

BIOMEDICAL SCIENCES

AND

CLINICAL INVESTIGATION

Braz J Med Biol Res, March 2010, Volume 43(3) 297-302

Highly sensitive C-reactive protein and male gender are independently related to the severity of coronary disease in patients with metabolic syndrome and an acute coronary event

C.M.C. Monteiro, L.F. Pinheiro, M.C. Izar, S.W. Barros, M.B. Vasco, S.M. Fischer, R.M. Povoa, S.A. Brandão, A.O. Santos, L. Oliveira, A.C. Carvalho and F.A.H. Fonseca

The Brazilian Journal of Medical and Biological Research is partially financed by
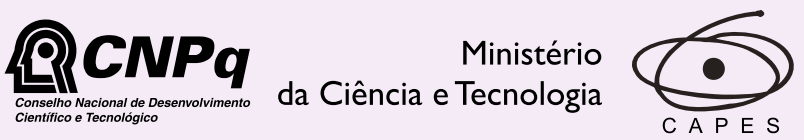

Ministério da Educação

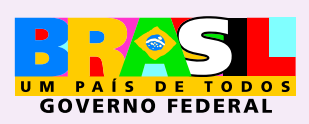




\title{
Highly sensitive C-reactive protein and male gender are independently related to the severity of coronary disease in patients with metabolic syndrome and an acute coronary event
}

\author{
C.M.C. Monteiro, L.F. Pinheiro, M.C. Izar, S.W. Barros, M.B. Vasco, S.M. Fischer, \\ R.M. Povoa, S.A. Brandão, A.O. Santos, L. Oliveira, A.C. Carvalho and F.A.H. Fonseca \\ Disciplina de Cardiologia, Escola Paulista de Medicina, Universidade Federal de São Paulo, São Paulo, SP, Brasil
}

\begin{abstract}
Patients with metabolic syndrome are at high-risk for development of atherosclerosis and cardiovascular events. The objective of this study was to examine the major determinants of coronary disease severity, including those coronary risk factors associated with metabolic syndrome, during the early period after an acute coronary episode. We tested the hypothesis that inflammatory markers, especially highly sensitive C-reactive protein (hsCRP), are related to coronary atherosclerosis, in addition to traditional coronary risk factors. Subjects of both genders aged 30 to 75 years $(N=116)$ were prospectively included if they had suffered a recent acute coronary syndrome (acute myocardial infarction or unstable angina pectoris requiring hospitalization) and if they had metabolic syndrome diagnosed according to the National Cholesterol Education Program/Adult Treatment Panel III. Patients were submitted to a coronary angiography and the burden of atherosclerosis was estimated by the Gensini score. The severity of coronary disease was correlated (Spearman's or Pearson's coefficient) with gender $(r=0.291, P=0.008)$, age $(r=$ $0.218, P=0.048)$, hsCRP $(r=0.256, P=0.020)$, ApoB/ApoA ratio $(r=0.233, P=0.041)$, and carotid intima-media thickness $(r$ $=0.236, P=0.041)$. After multiple linear regression, only male gender $(P=0.046)$ and hsCRP $(P=0.012)$ remained independently associated with the Gensini score. In this high-risk population, male gender and high levels of hsCRP, two variables that can be easily obtained, were associated with more extensive coronary disease, identifying patients with the highest potential of developing new coronary events.
\end{abstract}

Key words: Metabolic syndrome; Acute coronary syndrome; C-reactive protein; Gender; Gensini score

\section{Introduction}

Subjects with metabolic syndrome (MetS) are considered to be at high risk for coronary and cardiovascular events due to the clustering of cardiovascular risk factors, including central obesity, glucometabolic abnormalities, dyslipidemia, and increased blood pressure levels $(1,2)$. In addition, MetS at hospital admission for an acute coronary syndrome (ACS) episode was identified as a strong and independent early predictor of mortality and morbidity in patients with non-clinically diagnosed diabetes (3). On the other hand, traditional coronary risk algorithms such as the Framingham risk score do not include triglycerides, obesity, or impaired fasting glycemia as variables for coronary risk stratification (4).

Among novel risk markers, elevated highly sensitive
C-reactive protein (hsCRP) levels were related to the MetS, and both hsCRP and MetS were independent predictors of new cardiovascular events (5). Indeed, several cohort studies have shown that hsCRP evaluation adds prognostic information to the cardiovascular risk predicted by the Framingham risk score, as well as for subjects with MetS, especially those with concomitant subclinical carotid atherosclerosis (6).

Recently, the JUPITER trial (7), a primary prevention study for coronary artery disease, tested the predictive value of high hsCRP levels for the first occurrence of the major cardiovascular events in a very large population with relatively low LDL-C levels. An impressive relationship between myocardial infarction, stroke and thromboembolic events

Correspondence: F.A.H. Fonseca, Setor de Lípides, Aterosclerose e Biologia Vascular, Disciplina de Cardiologia, Departamento de Medicina, EPM, UNIFESP, Rua Pedro de Toledo, 276, 04039-030 São Paulo, SP, Brasil. Fax: +55-11-5087-9424/5087-9423. E-mail: fahfonseca@terra.com.br

Received May 15, 2009. Accepted November 4, 2009. Available online March 5, 2010. Published March $12,2010$. 
was observed with hsCRP, even in the absence of other traditional risk factors (7-9). Interestingly, in the JUPITER trial, over one third of the entire population consisted of patients with MetS (10). Previous studies have reported a different impact of metabolic syndrome according to gender (11-13) on the relative risk for cardiovascular disease, possibly related to differences in the components of the MetS and other concomitant risk factors. Concerning the severity of coronary disease, a recent study showed a positive association between the number of components of the metabolic syndrome and the Gensini score (14).

On the basis of these considerations, we determined the role of traditional and non-traditional risk factors, including hsCRP, parameters of hemostasis and glucometabolic abnormalities, on the severity of coronary artery disease in subjects with MetS after an ACS episode.

\section{Patients and Methods}

\section{Patients}

The study was conducted at São Paulo Hospital, Federal University of São Paulo, and was approved by the local Ethics Committee. Written informed consent was obtained from all patients.

Subjects of both genders aged 30 to 75 years $(N=116)$ were prospectively included if they had suffered a recent ACS event (acute myocardial infarction or unstable angina pectoris requiring hospitalization) and if they had MetS diagnosed according to the National Cholesterol Education Program/Adult Treatment Panel (NCEP/ATP III) (4), which includes three or more of the following criteria: waist circumference $>102 \mathrm{~cm}$ for men and $>88 \mathrm{~cm}$ for women; blood pressure $\geq 130 / 85 \mathrm{mmHg}$ or use of antihypertensive medication; plasma triglycerides $\geq 150 \mathrm{mg} / \mathrm{dL}$; HDL-C $<40$ $\mathrm{mg} / \mathrm{dL}$ for men and $<50 \mathrm{mg} / \mathrm{dL}$ for women; fasting glucose $\geq 110 \mathrm{mg} / \mathrm{dL}$ or known diabetes. None of these patients were under treatment with hypolipidemic agents within the last 4 weeks.

\section{Laboratory tests}

Fasting blood samples were obtained 1-3 days after hospital discharge for measurement of cholesterol and triglycerides using an automated enzymatic kit (Opera Bayer, Germany), and LDL-C was estimated with the Friedewald formula (15). ApoB, ApoA1, Lp(a) (Array 360 Beckmann, Germany), and hsCRP were measured by nephelometry (R100 Analyzer, Behringer, Germany). Plasma peroxidation was evaluated by the thiobarbituric acid reactive substance (TBARS) assay, which measures aldehyde formation. Fibrinogen, D-dimer, and factor VII were estimated by automated methods. Von Willebrand factor (vWF), and plasminogen-activator inhibitor-1 (PAI-1) were determined by enzyme-linked immunosorbent assay (ELISA). The homeostasis model for the assessment of insulin resistance (HOMA-IR) was calculated as insulin
$(\mathrm{mU} / \mathrm{L}) \times($ glucose $[\mathrm{mg} / \mathrm{dL}] \times 0.055) / 22.5$ (16). The insulinogenic index was calculated as the difference between the plasma insulin values obtained at 30 and 0 min of the oral glucose tolerance test (OGTT) divided by the difference between the corresponding plasma glucose values $(\Delta \mathrm{I} 30 / \Delta \mathrm{G} 30)$. Adiponectin was measured by ELISA using a commercial kit (Human Adiponectin/Acrp30 Immunoassay Quantiquine, R\&D Systems). Glycated hemoglobin (HbA1C) was measured by high performance liquid chromatography. Body mass index (BMI) and waist circumference were recorded, and seated blood pressure was determined in both arms after a 5-min rest.

\section{Coronary artery disease, intima media thickness, and flow-mediated dilation}

The severity of coronary atherosclerosis was examined by the Gensini score, which depends on the degree of luminal narrowing and the importance of the site of coronary stenosis (17). According to the score, the narrowing of the lumen of the coronary arteries is graded as follows: 1 point, $\leq 25 \%$; 2 points, $26-50 \%$; 4 points, $51-75 \%$; 8 points, $76-$ $90 \%$; 16 points, $91-99 \%$, and 32 points for total occlusion. In addition, this primary score is multiplied by a factor that takes into account the importance of the coronary artery containing the lesion ( 5 for the left main coronary artery, 2.5 for the proximal portion of the left anterior descending artery or proximal left circumflex artery and 1.5 for the midregion, 1 for the distal left anterior descending artery, and 1 for the mid-distal region of the left circumflex artery or right coronary artery). The sum of the total score obtained was used for statistical analysis.

The intima media thickness (IMT) of the carotid arteries was measured by ultrasonography with the patient in the supine position. High-resolution B-mode ultrasound images were scanned (Hewlett-Packard SONOS 5500, USA) with a linear transducer at frequencies $>7.5 \mathrm{MHz}$. Measurements were made in both the left and right common carotid arteries. IMT was assessed in the artery segment within $1 \mathrm{~cm}$ of the bifurcation (18). The scans were recorded on S-VHS tape and analyzed offline by an image analyst who was unaware of subject characteristics. The maximal IMT of both carotid arteries was used for statistical analysis. The intra- and inter-sonographer variability was $0.05 \pm 0.02$ and $0.07 \pm$ $0.04 \mathrm{~mm}$ for the IMT measurements, respectively.

Endothelial function was estimated by brachial flowmediated dilation (FMD) (19) measured in the morning after an overnight fast. After a 10-15 min rest, the brachial artery in the right antecubital fossa was visualized using a linear transducer $>7.5 \mathrm{MHz}$. Once the optimal image of the artery was achieved, the baseline vessel diameter was measured. Reactive hyperemia was induced by inflating the blood pressure cuff to $200 \mathrm{mmHg}$, or at least $50 \mathrm{mmHg}$ above systolic blood pressure, on the distal forearm for 5 min and then deflating the cuff. End-diastolic images were obtained at the time of onset of the QRS complex on the 
ECG. These images were acquired at baseline and $1 \mathrm{~min}$ after cuff deflation. The percent change from the baseline diameter to the value detected during reactive hyperemia was calculated to determine FMD. The intra- and intersonographer variability was $<1$ and $<2 \%$, respectively.

\section{Statistical analysis}

Data are reported as means \pm SEM, unless otherwise specified. Correlations of clinical and laboratory parameters with the Gensini score were initially determined using Pearson's coefficient for variables with normal distribution; for non-parametric variables, we used Spearman's correlation coefficient. Multivariate regression was performed considering the variables associated with the Gensini score. Differences between genders were compared by the unpaired $t$-test or the chi-square test. When necessary, variables were log-transformed. All tests were two-tailed, and the level of significance was set at $P<0.05$. All analyses were performed using the SPSS 11.5 for Windows.

\section{Results}

Similar mean values were obtained for men and women regarding age (56 \pm 1 vs $57 \pm 1$ years, respectively), BMI $\left(30.2 \pm 0.5\right.$ vs $\left.30.1 \pm 0.8 \mathrm{~kg} / \mathrm{m}^{2}\right)$, and the prevalence of hypertension (89.2 vs $90.5 \%$ ), diabetes mellitus (40.3 vs $54.4 \%$ ), or impaired glucose tolerance (31.9 vs $30.9 \%$ ). None of these differences were significant. Myocardial infarction as the presentation of ACS was more common among male subjects (55.4 vs $33.3 \%$; $P=0.022$ ).

Several glucometabolic parameters were observed, in-

Table 1. Major biochemical characteristics of the study population.

\begin{tabular}{lcc}
\hline Parameters & $\begin{array}{c}\text { Males } \\
(\mathrm{N}=74)\end{array}$ & $\begin{array}{c}\text { Females } \\
(\mathrm{N}=42)\end{array}$ \\
\hline Cholesterol $(\mathrm{mg} / \mathrm{dL})$ & $189 \pm 5$ & $197 \pm 6$ \\
LDL-C $(\mathrm{mg} / \mathrm{dL})$ & $115 \pm 4$ & $119 \pm 6$ \\
HDL-C $(\mathrm{mg} / \mathrm{dL})$ & $36 \pm 1$ & $47 \pm 2^{*}$ \\
Triglycerides $(\mathrm{mg} / \mathrm{dL})$ & $185 \pm 9$ & $165 \pm 13$ \\
ApoA1 $(\mathrm{mg} / \mathrm{dL})$ & $100 \pm 2$ & $119 \pm 3^{*}$ \\
ApoB $(\mathrm{mg} / \mathrm{dL})$ & $117 \pm 3$ & $110 \pm 4$ \\
ApoB/ApoA1 & $1.19 \pm 0.04$ & $0.95 \pm 0.04^{*}$ \\
Glucose $2 \mathrm{~h}(\mathrm{OGTT}, \mathrm{mg} / \mathrm{dL})$ & $208 \pm 12$ & $258 \pm 18^{*}$ \\
HbA1C $(\%)$ & $6.4 \pm 0.2$ & $6.8 \pm 0.3$ \\
HOMA-IR & $6.5 \pm 0.4$ & $7.6 \pm 0.8$ \\
$\Delta$ I30/ $\Delta \mathrm{G} 30$ & $112 \pm 12$ & $104 \pm 17$ \\
Adiponectin $(\mu \mathrm{g} / \mathrm{mL})$ & $6.2 \pm 0.6$ & $6.5 \pm 0.6$ \\
hsCRP $(\mathrm{mg} / \mathrm{L})$ & $18.2 \pm 2.3$ & $12.0 \pm 2.1^{*}$ \\
\hline
\end{tabular}

Data are reported as means \pm SEM. OGTT = oral glucose tolerance test; HOMA-IR = homeostasis model assessment of insulin resistance; $\Delta \mathrm{I} 30 / \Delta \mathrm{G} 30$ = insulinogenic index; hsCRP = highly sensitive $C$-reactive protein. ${ }^{*} P<0.05$ compared to males (unpaired $t$-test). cluding adiponectin, $\mathrm{HbA} 1 \mathrm{C}$, insulinogenic index, HOMA-IR, fasting glucose, and glucose levels $2 \mathrm{~h}$ after OGTT. Only the last parameter differed between the two groups, with female patients showing higher glucose levels $(P=0.026$ vs male subjects), as shown in Table 1. Among the components of MetS, male patients had a higher waist circumference (107 \pm 11 vs $101 \pm 10 \mathrm{~cm} ; \mathrm{P}=0.004)$, and lower HDL-C levels (36 \pm 1 vs $47 \pm 2 \mathrm{mg} / \mathrm{dL} ; \mathrm{P}=0.0001$ ) than female patients. In addition, a higher number of MetS components was observed among male subjects ( $P=0.001 \mathrm{vs}$ females). Male patients also presented a lower ApoA1 and a higher ApoB/ApoA1 ratio than female subjects (Table 1 ).

Higher serum PAl-1 levels were observed in males than in females ( $39 \pm 3$ vs $30 \pm 3 \mathrm{ng} / \mathrm{mL} ; \mathrm{P}=0.033)$, and significant differences were not observed between genders for fibrinogen ( $427 \pm 16$ vs $384 \pm 20 \mathrm{mg} / \mathrm{dL})$, factor VII $(124 \pm 15$ vs $129 \pm 12 \%)$, vWF (93 \pm 4 vs $102 \pm 6 \%)$, and D-dimer (1054 \pm 117 vs $968 \pm 151 \mathrm{ng} / \mathrm{mL})$. TBARS levels

Table 2. Correlations between the Gensini score and other variables.

\begin{tabular}{|c|c|}
\hline Variables & Correlation coefficient \\
\hline Gensini score $x$ gender $\#$ & $0.291^{*}$ \\
\hline Gensini score $\mathrm{x}$ age & $0.218^{*}$ \\
\hline Gensini score $\mathrm{x}$ hsCRP & $0.256^{*}$ \\
\hline Gensini score $\mathrm{x}$ apoB/apoA1 & $0.233^{*}$ \\
\hline Gensini score $x$ BMI & -0.088 \\
\hline Gensini score $\mathrm{x}$ waist circumference & 0.057 \\
\hline Gensini score $x$ SBP & 0.062 \\
\hline Gensini score $x$ DBP & -0.086 \\
\hline Gensini score $\mathrm{x}$ fasting glycemia & 0.135 \\
\hline Gensini score x HOMA-IR & -0.045 \\
\hline Gensini score $x$ cholesterol & 0.113 \\
\hline Gensini score $x$ LDL-C & 0.158 \\
\hline Gensini score $x$ HDL-C & -0.143 \\
\hline Gensini score $\mathrm{x}$ triglycerides & -0.023 \\
\hline Gensini score x Lp(a) & 0.013 \\
\hline Gensini score $x$ TBARS & -0.011 \\
\hline Gensini score $\mathrm{x}$ cIMT & $0.236^{*}$ \\
\hline Gensini score $\mathrm{x}$ factor VII & -0.002 \\
\hline Gensini score $\mathrm{x} v \mathrm{~W}$ factor & 0.008 \\
\hline Gensini score x D-dimer & 0.117 \\
\hline Gensini score x PAI-1 & 0.113 \\
\hline Gensini score $\mathrm{x}$ fibrinogen & 0.213 \\
\hline
\end{tabular}

hsCRP = highly sensitive $\mathrm{C}$-reactive protein; $\mathrm{BMI}=$ body mass index; $\mathrm{SBP}=$ systolic blood pressure; $\mathrm{DBP}=$ diastolic blood pressure; HOMA-IR = homeostasis model assessment of insulin resistance; TBARS = thiobarbituric acid reactive substances; cIMT = carotid intima-media thickness; $\mathrm{vW}$ factor $=$ von Willebrand factor; PAI-1 = plasminogen-activator inhibitor-1. ${ }^{*} \mathrm{P}<0.05$, variables significantly correlated with the Gensini score according to Pearson's or Spearman's correlation tests, when appropriate. \#Spearman's correlation coefficient. 
Table 3. Multiple linear regression of Gensini score and selected variables.

\begin{tabular}{|c|c|c|c|c|c|c|c|}
\hline \multirow[t]{2}{*}{ Variable } & \multicolumn{2}{|c|}{ Unstandardized coefficients } & \multirow{2}{*}{$\frac{\text { Standardized coefficients }}{\text { Beta }}$} & \multirow[t]{2}{*}{$t$} & \multirow[t]{2}{*}{$\mathrm{P}$} & \multicolumn{2}{|c|}{$95 \%$ confidence interval } \\
\hline & B & SEM & & & & Lower bound & Upper bound \\
\hline Constant & -52.833 & 24.025 & - & -2.199 & 0.031 & -100.737 & -4.928 \\
\hline Age & 0.510 & 0.315 & 0.178 & 1.617 & 0.110 & -0.119 & 1.138 \\
\hline Male* $^{*}$ & 11.447 & 5.635 & 0.220 & 2.032 & 0.046 & 0.212 & 22.682 \\
\hline clMT & 37.073 & 21.868 & 0.184 & 1.695 & 0.094 & -6.532 & 80.677 \\
\hline hsCRP* & 0.340 & 0.132 & 0.274 & 2.571 & 0.012 & 0.076 & 0.603 \\
\hline
\end{tabular}

Dependent variable: Gensini score. SEM = standard error of the mean. cIMT = carotid intima-media thickness; hsCRP = highly sensitive C-reactive protein. *Variables independently associated with the Gensini score.

were also comparable between groups (1.7 \pm 0.1 vs $1.7 \pm$ $0.1 \mathrm{nmol} / \mathrm{L})$, but hsCRP was higher in male subjects $(18.2$ \pm 2.3 vs $12.0 \pm 2.1 \mathrm{mg} / \mathrm{L} ; \mathrm{P}=0.049$ ).

The severity of coronary disease estimated by the Gensini score was higher among male than female patients ( $29 \pm 3$ vs $16 \pm 5$ points; $P=0.023$ ), and a trend to a lower brachial FMD was observed in male subjects (13 \pm 1 vs 16 $\pm 2 \%$; $P=0.098)$, while the maximal carotid IMT was similar in the two groups $(0.94 \pm 0.02$ vs $0.92 \pm 0.02 \mathrm{~mm})$.

Univariate analysis showed that, of all reported parameters, only five variables correlated with the Gensini score (Table 2). Multiple linear regression analysis was performed to identify those variables independently related to the Gensini score, and the final model included age, male gender, hsCRP, and carotid IMT. As shown in Table 3 , only hsCRP and male gender remained independently associated with the Gensini score.

\section{Discussion}

In subjects with MetS the likelihood of developing cardiovascular disease is approximately twice that observed in those who do not present the syndrome, even after adjustment for established risk factors (20-22). On this basis, patients with MetS should constitute a high risk group for further events or complications. In this context, our study found hsCRP levels and male gender as independent variables related to the severity of coronary disease.

Our initial hypothesis was based on the concept of the relationship between insulin resistance and MetS. Thus, we believed that the extent and clinical features of coronary artery disease should be related to glucometabolic, lipid and hemostasis abnormalities. However, we found that variables such as HDL-C, triglycerides, glucose, insulin, and HOMA-IR were not significantly related to the extent of coronary artery disease evaluated by the Gensini score. In the Multi-Ethnic Study of Atherosclerosis (MESA) (23), the association of insulin resistance and MetS with subclinical atherosclerosis was also examined, but these investigators did not detect a significant relationship between HOMA-IR and the amount of coronary artery calcium. Indeed, as stated above, we did not identify any parameter of hemostasis that correlated with the severity of atherosclerosis.

Sex-specific differences reported in the general population regarding cardiovascular or coronary disease mortality are outstandingly modified in diabetic populations. In the San Antonio Heart Study (24), when diabetes occurred with MetS, women with both features had a 14-fold increased risk of coronary heart disease mortality, whereas men had only a 4-fold increased risk. Our study showed that, at least when the glucometabolic profiles were similar between genders, male subjects with MetS at the time of ACS had more advanced atherosclerosis than female patients. In addition, a diagnosis of type 2 diabetes or impaired glucose tolerance was made in approximately $80 \%$ of the entire population, with similar rates for men and women. A positive association between increasing number of ATP III MetS components and coronary risk was reported in the Atherosclerosis Risk in Communities study, with high blood pressure and low HDL-C having the strongest effect (5). We found similar values for blood pressure between the two groups, but lower HDL-C levels among male subjects, who also had a higher number of MetS components. Post hoc analysis of the Treating to New Targets (TNT) study (25) showed that, among inpatients with coronary heart disease, significantly more patients with MetS had a major cardiovascular event at a median follow-up of 4.9 years than patients without MetS.

The association of MetS with early carotid atherosclerosis was examined in a large cohort of hypertensive patients (26). Baseline carotid IMT was slightly greater among patients with MetS than among patients without the condition. The impact of the MetS components on carotid IMT examined in another trial (27) showed gender-based differences in the mechanisms of MetS-induced atherosclerosis (central obesity for men only, triglycerides for women only, whereas systolic blood pressure was significantly associated with the baseline value and progression of IMT for both men and women). We obtained similar carotid IMT for the two genders in spite of significant gender differences in the severity of coronary disease. Recently, Kasai et al. (28) reported a mean Gensini score of 32.8 for males and 
21.9 for females with MetS according to the NCEP ATP III definition among patients who had undergone elective first coronary angiography. A positive association was found between the extension of coronary artery disease and the number of MetS components, and gender-related differences were also reported. However, in the study cited above, differences in ages between genders (mean \pm SD) were relatively small $(63.9 \pm 10.1$ years for males and 67.6 \pm 11.5 years for females) (28), contributing in part to these results. In fact, it is well known that cardiovascular events, as well as the progression of coronary atherosclerosis, usually occur earlier in men than in women as reported in a large and multiethnic cohort (29).

The contribution of low-grade inflammation in the development of plaques has been recognized in the pathophysiology of atherosclerosis. In this context, hsCRP has been proposed as the most promising marker of cardiovascular events and the JUPITER trial (7-10), which included a considerable number of patients of both genders with MetS and high CRP levels, was prematurely ended due to the unequivocal benefit of statin treatment for these subjects. In our patients, after adjustment by regression analysis, male gender and hsCRP levels were the only significant variables associated with the extent of coronary artery disease. Surprisingly, in our study no single glucometabolic variable was associated with the extent of coronary disease. However, both hsCRP levels and altered glycemia seem to be predictors of in-hospital cardiovascular events (30), and we recently reported high rates of glucometabolic disturbances among patients with MetS after an acute coronary event (31).

\section{Limitations}

This study was conducted few days after an ACS, a fact that might have contributed to lower lipid levels and blood pressure than in stable clinical conditions before the ACS. In addition, at this time, high fasting glucose levels could be related to stress-induced hyperglycemia. All of these variables are components of the MetS. However, this is a common clinical scenario and the data collected with these

\section{References}

1. Lakka HM, Laaksonen DE, Lakka TA, Niskanen LK, Kumpusalo $\mathrm{E}$, Tuomilehto J, et al. The metabolic syndrome and total and cardiovascular disease mortality in middle-aged men. JAMA 2002; 288: 2709-2716.

2. Lamarche B, Lemieux I, Despres JP. The small, dense LDL phenotype and the risk of coronary heart disease: epidemiology, patho-physiology and therapeutic aspects. Diabetes Metab 1999; 25: 199-211.

3. Feinberg MS, Schwartz R, Tanne D, Fisman EZ, Hod H, Zahger $\mathrm{D}$, et al. Impact of the metabolic syndrome on the clinical outcomes of non-clinically diagnosed diabetic patients with acute coronary syndrome. Am J Cardiol 2007; possible biases were still useful to identify those patients with more extensive coronary disease.

The best criteria for MetS definition in ACS patients are still being debated. According to some investigators, a modified ATP definition for MetS included blood glucose levels $>140 \mathrm{mg} / \mathrm{dL}$ (as occasional blood glucose at admission), BMI $>28 \mathrm{~kg} / \mathrm{m}^{2}$ (instead of abdominal circumference), and selfreport of preexisting hypertension (3). In the INTERHEART study (32), the authors also included self-reported history of hypertension due to the use of beta-blockers, nitrates, and angiotensin-converting enzyme inhibitors, all of them capable of affecting blood pressure levels during hospitalization. However, according to a recent hypertension survey in Brazil (33), not all patients are aware of their disease, and therefore a self-reported history of hypertension can underestimate the diagnosis of hypertension.

We did not evaluate ACS patients without MetS to determine if the correlation of hsCRP levels with the severity of coronary disease can be extended to these patients. However, a recent study confirmed the correlation of this variable with the Gensini score $(r=0.42, P<0.001)$ among patients with acute or previous myocardial infarction as well as with stable or unstable angina pectoris in addition to controls who undergo coronary angiography (34).

To the best of our knowledge, no previous study has described the entire complex of gender-related differences in the components of MetS, together with traditional and non-traditional coronary risk markers, and the extent of atherosclerosis among patients with MetS after ACS. We demonstrated that during the early period after an acute coronary syndrome, among several biochemical and imaging tests, inexpensive parameters such as hsCRP and male gender best predict the severity of coronary artery disease.

\section{Acknowledgments}

Research supported by FAPESP. C.M.C. Monteiro is the recipient of a research fellowship from CNPq.

99: 667-672.

4. Executive Summary of the Third Report of the National Cholesterol Education Program (NCEP) Expert Panel on Detection, Evaluation, and Treatment of High Blood Cholesterol in Adults (Adult Treatment Panel III). JAMA 2001; 285: 2486-2497.

5. Rutter MK, Meigs JB, Sullivan LM, D'Agostino RB Sr, Wilson PW. C-reactive protein, the metabolic syndrome, and prediction of cardiovascular events in the Framingham Offspring Study. Circulation 2004; 110: 380-385.

6. Cao JJ, Arnold AM, Manolio TA, Polak JF, Psaty BM, Hirsch $\mathrm{CH}$, et al. Association of carotid artery intima-media thick- 
ness, plaques, and C-reactive protein with future cardiovascular disease and all-cause mortality: the Cardiovascular Health Study. Circulation 2007; 116: 32-38.

7. Ridker PM, Danielson E, Fonseca FA, Genest J, Gotto AM $\mathrm{Jr}$, Kastelein JJ, et al. Rosuvastatin to prevent vascular events in men and women with elevated C-reactive protein. N Engl J Med 2008; 359: 2195-2207.

8. Ridker PM, Danielson E, Fonseca FA, Genest J, Gotto AM $\mathrm{Jr}$, Kastelein JJ, et al. Reduction in C-reactive protein and LDL cholesterol and cardiovascular event rates after initiation of rosuvastatin: a prospective study of the JUPITER trial. Lancet 2009; 373: 1175-1182.

9. Glynn RJ, Danielson E, Fonseca FA, Genest J, Gotto AM Jr, Kastelein $\mathrm{JJ}$, et al. A randomized trial of rosuvastatin in the prevention of venous thromboembolism. N Engl J Med 2009; 360: 1851-1861.

10. Ridker PM, Fonseca FA, Genest J, Gotto AM, Kastelein JJ, Khurmi NS, et al. Baseline characteristics of participants in the JUPITER trial, a randomized placebo-controlled primary prevention trial of statin therapy among individuals with low low-density lipoprotein cholesterol and elevated high-sensitivity C-reactive protein. Am J Cardiol 2007; 100: 1659-1664.

11. McNeill AM, Rosamond WD, Girman CJ, Golden SH, Schmidt MI, East HE, et al. The metabolic syndrome and 11-year risk of incident cardiovascular disease in the atherosclerosis risk in communities study. Diabetes Care 2005; 28 : 385-390.

12. Hunt KJ, Resendez RG, Williams K, Haffner SM, Stern MP. National Cholesterol Education Program versus World Health Organization metabolic syndrome in relation to allcause and cardiovascular mortality in the San Antonio Heart Study. Circulation 2004; 110: 1251-1257.

13. Ridker PM, Wilson PW, Grundy SM. Should C-reactive protein be added to metabolic syndrome and to assessment of global cardiovascular risk? Circulation 2004; 109: 28182825.

14. Yavuz B, Kabakci G, Aksoy H, Tulumen E, Deveci OS, Aytemir K, et al. Determining the relationship between metabolic syndrome score and angiographic severity of coronary artery disease. Int J Clin Pract 2008; 62: 717-722.

15. Friedewald WT, Levy RI, Fredrickson DS. Estimation of the concentration of low-density lipoprotein cholesterol in plasma, without use of the preparative ultracentrifuge. Clin Chem 1972; 18: 499-502.

16. Matthews DR, Hosker JP, Rudenski AS, Naylor BA, Treacher DF, Turner RC. Homeostasis model assessment: insulin resistance and beta-cell function from fasting plasma glucose and insulin concentrations in man. Diabetologia 1985; 28 : 412-419.

17. Gensini GG. A more meaningful scoring system for determining the severity of coronary heart disease. Am J Cardiol 1983; 51: 606 .

18. Skilton MR, Moulin P, Serusclat A, Nony P, Bonnet F. A comparison of the NCEP-ATPIII, IDF and AHA/NHLBI metabolic syndrome definitions with relation to early carotid atherosclerosis in subjects with hypercholesterolemia or at risk of CVD: evidence for sex-specific differences. Atherosclerosis 2007; 190: 416-422.

19. Faulx MD, Wright AT, Hoit BD. Detection of endothelial dysfunction with brachial artery ultrasound scanning. Am Heart J 2003; 145: 943-951.
20. Isomaa B, Almgren P, Tuomi T, Forsen B, Lahti K, Nissen $\mathrm{M}$, et al. Cardiovascular morbidity and mortality associated with the metabolic syndrome. Diabetes Care 2001; 24: 683689.

21. Bonora E, Kiechl S, Willeit J, Oberhollenzer F, Egger G, Bonadonna RC, et al. Carotid atherosclerosis and coronary heart disease in the metabolic syndrome: prospective data from the Bruneck study. Diabetes Care 2003; 26: 12511257.

22. Ford ES. The metabolic syndrome and mortality from cardiovascular disease and all-causes: findings from the National Health and Nutrition Examination Survey II Mortality Study. Atherosclerosis 2004; 173: 309-314.

23. Bertoni AG, Wong ND, Shea S, Ma S, Liu K, Preethi S, et al. Insulin resistance, metabolic syndrome, and subclinical atherosclerosis: the Multi-Ethnic Study of Atherosclerosis (MESA). Diabetes Care 2007; 30: 2951-2956.

24. Hunt KJ, Williams K, Hazuda HP, Stern MP, Haffner SM. The metabolic syndrome and the impact of diabetes on coronary heart disease mortality in women and men: the San Antonio Heart Study. Ann Epidemiol 2007; 17: 870-877.

25. Deedwania P, Barter P, Carmena R, Fruchart JC, Grundy SM, Haffner S, et al. Reduction of low-density lipoprotein cholesterol in patients with coronary heart disease and metabolic syndrome: analysis of the Treating to New Targets study. Lancet 2006; 368: 919-928.

26. Zanchetti A, Hennig M, Baurecht H, Tang R, Cuspidi C, Carugo $S$, et al. Prevalence and incidence of the metabolic syndrome in the European Lacidipine Study on Atherosclerosis (ELSA) and its relation with carotid intima-media thickness. J Hypertens 2007; 25: 2463-2470.

27. Fan AZ. Metabolic syndrome and progression of atherosclerosis among middle-aged US adults. J Atheroscler Thromb 2006; 13: 46-54.

28. Kasai T, Miyauchi K, Kubota N, Tamura H, Kojima T, Yokoyama K, et al. The relationship between the metabolic syndrome defined by various criteria and the extent of coronary artery disease. Atherosclerosis 2008; 197: 944-950.

29. Kronmal RA, McClelland RL, Detrano R, Shea S, Lima JA, Cushman M, et al. Risk factors for the progression of coronary artery calcification in asymptomatic subjects: results from the Multi-Ethnic Study of Atherosclerosis (MESA). Circulation 2007; 115: 2722-2730.

30. Duarte ER, Pellanda LC, Portal VL. [Inflammatory, lipid, and metabolic profile in acute ischemic syndrome: correlation with hospital and posthospital events]. Arq Bras Cardiol 2005; 84: 122-129.

31. Monteiro CM, Oliveira L, Izar MC, Helfenstein T, Santos AO, Fischer SM, et al. Early glucometabolic profile in patients with acute coronary syndromes and metabolic syndrome. Arq Bras Cardiol 2009; 92: 89-99.

32. Yusuf S, Hawken S, Ounpuu S, Dans T, Avezum A, Lanas F, et al. Effect of potentially modifiable risk factors associated with myocardial infarction in 52 countries (the INTERHEART Study): case-control study. Lancet 2004; 364: 937-952.

33. Moreira GC, Cipullo JP, Martin JF, Ciorlia LA, Godoy MR, Cesarino $\mathrm{CB}$, et al. Evaluation of the awareness, control and cost-effectiveness of hypertension treatment in a Brazilian city: populational study. J Hypertens 2009; 27: 1900-1907.

34. Liu Y, Li X, Peng D, Tan Z, Liu H, Qing Y, et al. Usefulness of serum cathepsin $\mathrm{L}$ as an independent biomarker in patients with coronary heart disease. Am J Cardiol 2009; 103: 476-481. 